\title{
Methylphenidate Enhances Early-Stage Sensory Processing and Rodent Performance of a Visual Signal Detection Task
}

\author{
Rachel L Navarra*, ${ }^{*, 3}$, Brian D Clark², Andrew T Gargiulo² and Barry D Waterhouse ${ }^{2}$ \\ 'Department of Pharmacology and Physiology, Drexel University College of Medicine, Philadelphia, PA, USA; ${ }^{2}$ Department of Neurobiology and \\ Anatomy, Drexel University College of Medicine, Philadelphia, PA, USA
}

\begin{abstract}
Methylphenidate $(\mathrm{MPH})$ is used clinically to treat attention-deficit/hyperactivity disorder (ADHD) and off-label as a performance-enhancing agent in healthy individuals. MPH enhances catecholamine transmission via blockade of norepinephrine (NE) and dopamine (DA) reuptake transporters. However, it is not clear how this action affects neural circuits performing cognitive and sensorimotor functions driving performance enhancement. The dorsal lateral geniculate nucleus ( $d L G N$ ) is the primary thalamic relay for visual information from the retina to the cortex and is densely innervated by NE-containing fibers from the locus coeruleus (LC), a pathway known to modulate statedependent sensory processing. Here, MPH was evaluated for its potential to alter stimulus-driven sensory responses and behavioral outcomes during performance of a visual signal detection task. MPH enhanced activity within individual neurons, ensembles of neurons, and visually-evoked potentials (VEPs) in response to task light cues, while increasing coherence within theta and beta oscillatory frequency bands. $\mathrm{MPH}$ also improved reaction times to make correct responses, indicating more efficient behavioral performance. Improvements in reaction speed were highly correlated with faster VEP latencies. Finally, immunostaining revealed that catecholamine innervation of the dLGN is solely noradrenergic. This work suggests that $\mathrm{MPH}$, acting via noradrenergic mechanisms, can substantially affect early-stage sensory signal processing and subsequent behavioral outcomes.

Neuropsychopharmacology (2017) 42, I326-1337; doi:I0.1038/npp.2016.267; published online 4 January 2017
\end{abstract}

\section{INTRODUCTION}

Methylphenidate (MPH; Ritalin) is a prescription psychostimulant drug used as a first-line treatment for attention deficit hyperactivity disorder (ADHD), a common neurodevelopmental disorder characterized by inattention, hyperactivity, and impulsive behavior (Weyandt et al, 2014). MPH is also frequently used off-label as a performance-enhancing drug by healthy individuals to achieve greater accuracy and speed, or improve behavioral efficiency while being engaged in goal-driven tasks (Franke et al, 2014; Sahakian and Morein-Zamir, 2015). Off-label use of MPH benefits various aspects of academic, athletic, and social performance, ranging from faster processing and reactions to surrounding stimuli within dynamic environments, improved concentration, and elevation of mood (Svetlov et al, 2007). Despite the widespread use and decades of investigation, the means through which psychostimulants such as MPH regulate sensorimotor and cognitive neural circuit function and enhance performance are poorly understood.

*Correspondence: Dr RL Navarra, Department of Pharmacology and Physiology, Drexel University College of Medicine, 245 N I5th Street, Philadelphia, PA 19102, USA. E-mail: rachel.lynn.navarra@gmail.com

${ }^{3}$ Current address: Department of Cell Biology and Neuroscience, Rowan University School of Medicine, Stratford, NJ 08084, USA. Tel: 856566 6829, Fax: 856566 6195, E-mail: navarra@rowan.edu

Received 6 September 2016; revised 3 November 2016; accepted 28 November 2016; accepted article preview online 2 December 2016
Sensory processing is an essential element of effective cognitive and motor function. Optimal processing of sensory information is critical for maintaining focus, facilitating efficient behavioral responses, and completing successful goal-directed behaviors. The ability to distinguish neural representations of important sensory stimuli from the environment is crucial for these processes. Interestingly, inappropriate processing of sensory stimuli is a common feature of many neurological disorders including ADHD (Kim et al, 2014; Mazer, 2011; Pfeiffer et al, 2015). There have been multiple reports demonstrating psychostimulantmediated alteration of various dimensions of sensory processing (Agster et al, 2011; Drouin et al, 2007; Jonkman et al, 1997; Martin et al, 2008; Navarra et al, 2013), suggesting that such actions may contribute significantly to the performance-enhancing properties of these agents.

Sensory processing is modulated by several mechanisms to extract salient information from complex and dynamic environments. The locus coeruleus (LC)-norepinephrine (NE) system is prominently involved in state-dependent regulation of sensory signal transmission (Berridge and Waterhouse, 2003). For example, NE enhances 'signal-tonoise' ratios of sensory-evoked neuronal responses throughout the brain (Berridge and Waterhouse, 2003). Correspondingly, MPH blocks the reuptake of dopamine (DA) and NE, thereby increasing catecholamine neurotransmission (Kuczenski and Segal, 2001; Volkow et al, 2002), suggesting that psychostimulants acting through this mechanism can 
produce NE-like facilitation of signal processing in noradrenergic terminal fields. Indeed, previous studies have demonstrated $\mathrm{MPH}$-mediated enhancement of sensory neuron function within cortical and thalamic circuits of the anesthetized rat (Drouin et al, 2007; Navarra et al, 2013). However, the impact of noradrenergic or psychostimulant modulation of sensory-evoked responses on behavioral outcomes has not been demonstrated.

The visual system has long provided a means of investigating modulation of sensory processing during performance of goal-directed behaviors (Kastner and Pinsk, 2004). The dorsal lateral geniculate nucleus (dLGN), the primary thalamic relay for visual information to the cortex, is of particular interest because it receives substantial input from the LC-NE system, yet sparse or nonexistent DA innervation (García-Cabezas et al, 2009; Kayama, 1985; Kromer and Moore, 1980). Electrical stimulation of the LC or local administration of NE facilitates dLGN neuronal responses to excitatory stimuli via $\alpha-1$ postsynaptic adrenoceptors (Rogawski and Aghajanian, 1980a). In addition, we recently demonstrated that $\mathrm{MPH}$ and atomoxetine, a NE-specific reuptake blocker, decrease the latency and increase the magnitude of dLGN neuronal responses to light stimuli in anesthetized rats (Navarra et al, 2013), further supporting a key role for NE-mediated augmentation of sensory signal processing in psychostimulant-driven performance enhancement. Although experiments in anesthetized preparations offer substantial opportunity to examine drug actions under stable, well-controlled conditions, they cannot account for the dynamics and complexity of physiological interactions in the brains of waking animals (Devilbiss and Waterhouse, 2003). In the present study, we assessed single- and multi-unit discharges and visuallyevoked potentials within the dLGN in response to light cues and behavioral measures during performance of a visual signal detection task both before and after administration of $\mathrm{MPH}$. We also examined catecholamine fibers in the dLGN to evaluate the potential roles of NE versus DA in MPHinduced modulation of dLGN responsiveness to visual stimuli.

\section{MATERIALS AND METHODS}

\section{Animals}

Thirteen male Sprague-Dawley rats (300-500 g) were housed in pairs before study and individually after surgery (Taconic; Germantown, NY) in a $12: 12 \mathrm{~h}$ inverted light cycle facility, with ad libitum access to food and water. Following acclimation, 10 rats were water restricted to $85-90 \%$ of their free-feeding body weight before daily behavioral training. All procedures were conducted in accordance with the guidelines of the National Institutes of Health Guide for the Care and Use of Laboratory Animals and approval of the Drexel University Institutional Animal Care and Use Committee.

\section{Behavioral Training}

Rats were trained in operant chambers controlled with MED-PC software (Med Associates, St Albans, VT). Chambers were equipped with a house light, two retractable response levers, lights (one central LED and two incandescent lights above each lever), a centrally located nose-poke port on the front wall, with a water dipper for reward delivery $(40 \mu \mathrm{l})$ on the rear wall.

An operant schedule (Figure 1a) was used to assess components of sensory signal processing and detection performance in a task developed from previously reported paradigms (Jentsch et al, 2009; Kimchi and Laubach, 2009; McGaughy and Sarter, 1995). To standardize illumination of receptive fields of dLGN neurons (Fukuda et al, 1979), an obligatory observing response was inserted into the task to ensure all stimuli were received from a fixed orientation, that is, rats were required to maintain a nose-poke position for $1500 \mathrm{~ms}$ directly below the LED stimulus light in order to initiate trials. Illumination of the nose-port indicated that a trial could be initiated. Following successful maintenance of the observing response, levers were extended and subjects reported whether a brief $(5 \mathrm{~ms})$ flash of light from the central LED had been detected by pressing a lever (eg, yes: left lever; no: right lever) to receive a water reward for a correct choice. On signal trials, which occurred randomly in $60 \%$ of trials, a correct response ('hit') was followed with $5 \mathrm{~s}$ presentation of a water reward, whereas an incorrect response ('miss') resulted in a $5 \mathrm{~s}$ timeout. On nonsignal trials, a correct response ('correct rejection, CR') was followed by a reward, whereas an incorrect response ('false alarm, FA') resulted in a timeout. Omissions were recorded for any trial in which the full observing response was maintained but no lever press response was made. For both signal and nonsignal trials, if a subject failed to maintain a full $1500 \mathrm{~ms}$ observing response, the levers did not extend, and a new trial had to be initiated. Inter-trial intervals lasted at least $5 \mathrm{~s}$ during presentation of rewards or timeouts before self-motivated initiation of subsequent trials. Each session ended after 100 successful trials or $30 \mathrm{~min}$. Animals were trained until criterion performance was achieved $(>80 \%$ correct responses over 3 consecutive test sessions with $<20 \%$ omissions).

\section{Surgery}

Once criterion performance was achieved, eight-wire microelectrode bundles were implanted bilaterally into the dLGNs as previously described (Navarra et al, 2013). Animals recovered for at least 1 week before recording and then retrained to presurgery baseline performance.

\section{Drugs}

MPH (Sigma-Aldrich, St Louis, MO), dissolved in sterile saline, was administered via i.p. injection in a dosing volume of $1 \mathrm{mg} / \mathrm{ml}$. Doses of MPH (0.5 and $2 \mathrm{mg} / \mathrm{kg}, 15 \mathrm{~min}$ before task) were based on previous reports of MPH enhancement of cognitive function in normal adult rats (Berridge et al, 2012; Bizarro et al, 2004; Jentsch et al, 2009; Navarra et al, 2008; Paterson et al, 2011; Robinson, 2012). These doses also fall within the range that produces therapeutic plasma concentrations in ADHD patients $(8-40 \mathrm{ng} / \mathrm{ml}$ ) and improves cognitive function in healthy adult humans (Berridge et al, 2006). A minimum of 2 days was used as a washout period between drug doses. 
a

Nose-poke Exit, Behavioral Choice

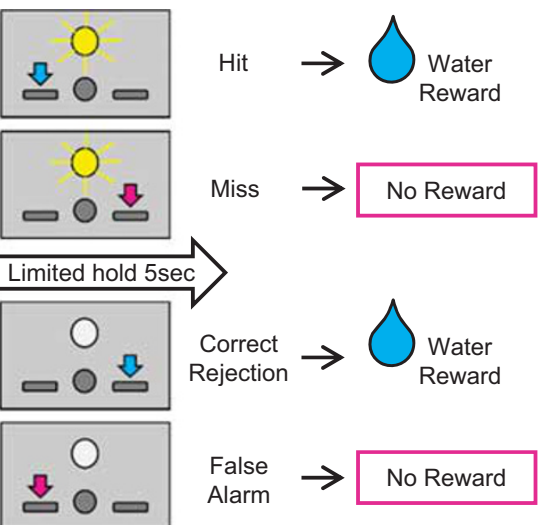

b

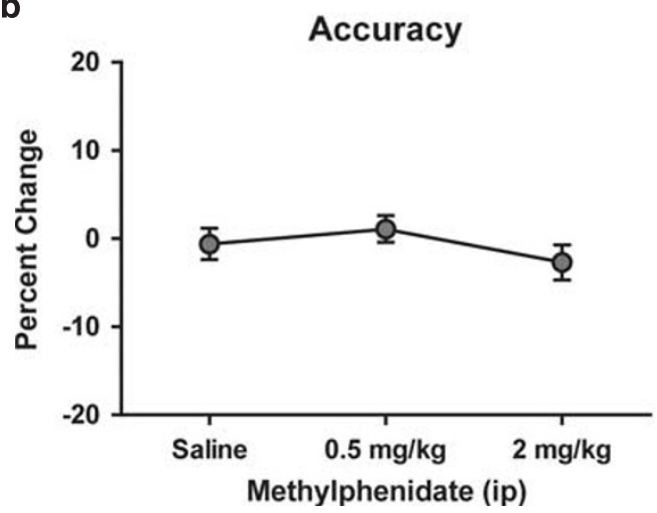

C

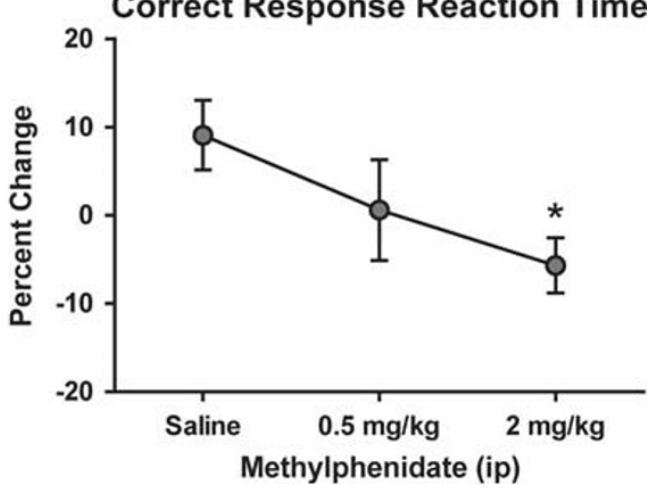

Figure I MPH effects on behavior during performance of the visual signal detection task. (a) Flow scheme of the behavioral paradigm. Rats were trained to initiate trials by maintaining an observing response (to ensure that stimuli are received from a fixed orientation). During the observing response, a LED light would flash briefly on signal trials only. If the observing response was maintained for $1500 \mathrm{~ms}$, levers were extended and subjects reported whether the signal was detected (eg, yes: left lever; and no: right lever) to receive a water reward for a correct choice. On signal trials, a 'Hit' was rewarded and a 'Miss' was incorrect. On nonsignal trials, a 'Correct Rejection' was rewarded and a 'False Alarm' was incorrect. (b, c) Percent change values \pm SEM for accuracy and reaction time measures of signal detection task behavior, respectively ( $n=6$ rats). Percent change was calculated as ((posttreatment-pretreatment)/ pretreatment $\times 100$ ). Accuracy $=$ proportion of correct responses calculated as (hits+correct rejections)/(no. of total trials completed)). Correct response reaction time $=$ mean latency from lever extension to correct response (hits and correct rejections combined). $* P<0.025$.

\section{Electrophysiological Recordings during Task Performance}

On test days, recordings were made over two runs of the task; the first run followed saline administration and the second followed a counterbalanced drug dosing design (saline, 0.5 , and $2 \mathrm{mg} / \mathrm{kg}$ ). This test day design allowed behavioral measures and light-evoked responses of dLGN neurons to be compared with their own baseline values on a given day and to be expressed as percent change ((posttreatment - pretreatment)/pretreatment $\times 100)$. Druginduced changes were then compared across doses of MPH.

A within-subjects behavioral design was used to evaluate drug effects on signal detection performance and the relation between behavioral performance and the modulation of light-evoked neuronal activity. Percent accuracy ((hits + correct rejections/no. of total trials completed $\times 100)$, stimulus detectability $\left(\mathrm{d}^{\prime}=\mathrm{Z}(\mathrm{N})-\mathrm{Z}(\mathrm{SN})\right.$, where $\mathrm{Z}(\mathrm{N})=$ the $Z$ score of the Noise Distribution and $Z(S N)=Z$ score of the Signal+Noise Distribution as described in Berridge et al (2012)), hit rate (hits/no. of signal trials), miss rate (misses/ no. of signal trials), CR rate (CRs/no. of nonsignal trials), FA rate (FAs/no. of nonsignal trials), omission rate (omissions/ no. of total trials), and mean lever press reaction times were calculated for both runs. Run-to-run percent changes in accuracy and reaction time were used to compare behavioral effects of each dose.

Multi-channel, multi-neuron recordings were used to evaluate the effects of MPH on dLGN responsivity to stimulus lights during performance of the task. Neural signals were amplified and discriminated using a Plexon MAP system (Plexon, Dallas, TX). Spike channels were digitized at $40 \mathrm{kHz}$ and band pass filtered from $250 \mathrm{~Hz}$ to $8 \mathrm{kHz}$, whereas local field potentials were digitized at $1 \mathrm{kHz}$ and band pass filtered from 0.7 to $170 \mathrm{~Hz}$, both with 12-bit resolution.

\section{Electrophysiological Analysis}

Light-evoked activity was sorted offline for multi-unit ensemble or single-unit discrimination according to waveform characteristics and inter-spike interval distribution as previously described (Navarra et al, 2013). PSTHs 
representing single-unit responses were constructed for each drug condition ( $1 \mathrm{~ms}$ bins, smoothed with a 3-bin boxcar function). Data were analyzed using custom MATLAB routines (MathWorks). Primary peaks in PSTHs were characterized by latency to response onset and to maximum response, maximum response amplitude, and response area (Navarra et al, 2013).

Visually-evoked potentials (VEPs) were extracted from the local field potential (LFP) recordings, averaged for each drug condition, and analyzed for latency and amplitude of waveform peaks and troughs using custom MATLAB routines. Similar to thalamic VEPs reported by Meeren et al (1998), VEPs recorded in rats performing the signal detection task generally exhibited prominent P30 and N54 shapes (positive and negative deflections of the waveform 30 and $54 \mathrm{~ms}$ following the onset of target stimulus presentation, respectively). Coherence of LFP oscillatory activity between light-evoked channels within the dLGN was calculated across frequencies (delta $1-4 \mathrm{~Hz}$, theta $5-8 \mathrm{~Hz}$, alpha $8-12 \mathrm{~Hz}$, beta $12-20 \mathrm{~Hz}$, and gamma $20-40 \mathrm{~Hz}$ ), for each interval of behavior using Neuroexplorer. Drug-induced changes of VEPs and dLGN coherence were evaluated across treatments.

\section{Histology}

After electrophysiology experiments, animals were deeply anesthetized and perfused with $4 \%$ paraformaldehyde. Brains were sectioned $(30 \mu \mathrm{m})$, mounted, and counterstained with neutral red for verification of electrode tracks terminating in the dLGN.

\section{Statistical Analysis}

Statistical analyses were performed using Prism (GraphPad). Repeated measures ANOVA and planned contrasts with Bonferroni corrections (each dose of $\mathrm{MPH}$ compared with saline control, corrected $\alpha=0.025$ ) were conducted to evaluate the effects of $\mathrm{MPH}$ on performance measures. Analysis of reaction latencies was restricted to correct trials (because performance levels were consistently high, sample sizes of incorrect trials were often negligible). Responses with the longest latencies (up to $5 \mathrm{~s}$ ) appeared to result from random lever pressing, rather than engagement with the signal detection task. To attenuate the effect of this nuisance variable, which heavily skewed the samples, the three longest and shortest latency responses in each sample were trimmed before computation of mean response latency (Howell, 2008). Percent change in latency for hits, correct rejections, and the combined correct response reaction time (mean of hit and correct rejection average change) were compared across treatment levels. KruskalWallis tests were conducted to compare percent changes for properties of light-evoked responses within the dLGN across treatment days and Dunn's multiple comparisons were performed following determination of an overall effect. Two-way repeated measures ANOVA with Bonferroni's multiple comparisons tests were used for druginduced effects on coherence across frequency bands within LFP oscillatory activity. Spearman's correlations were computed between hit reaction latency and dLGN light-evoked response latencies on correctly responded signal trials.

\section{RESULTS}

Of the 10 rats trained in the task and surgically implanted with dLGN electrodes, full behavioral pharmacology and electrophysiological data were collected from 6 animals. Three rats were excluded because of health or behavioral issues that led to incomplete pharmacological evaluation. One additional rat was excluded because of loss of electrode integrity following implantation.

\section{MPH Effects on Behavior}

All rats acquired the signal detection task and performed with $>90 \%$ accuracy. MPH did not significantly affect accuracy $(\mathrm{F}(1.848,9.240)=1.129, p=0.3593$; Figure $1 \mathrm{~b})$, d' $(\mathrm{F}(1.799,8.996)=0.7566, \quad p=0.4836), \quad$ hit rate $(\mathrm{F}(1.836$, $9.182)=1.859, p=0.2102)$, correct rejection rate $(\mathrm{F}(1.414$, $7.071)=0.0675, p=0.878)$, or false alarm rate $(\mathrm{F}(1.488$, $7.439)=0.04108, p=0.9219)$. In these highly trained animals, miss and omission rates could not be analyzed because of such low occurrence or absence of these responses. MPH did not have a significant overall effect on mean reaction time for hits, correct rejections, or combined correct responses $(\mathrm{F}(1.922$, $9.610)=1.615, p=0.2482 ; \mathrm{F}(1.380,6.902)=1.554, p=0.2663$; and $\mathrm{F}(1.283,6.414)=1.917, p=0.2178$, respectively). Planned contrasts reveal however that $\mathrm{MPH}(2 \mathrm{mg} / \mathrm{kg})$ significantly decreased latency of combined correct responses compared with saline control ( $p=0.0118$; Figure 1c).

\section{MPH Effects on Multi-Unit Ensemble Activity}

The effects of MPH on dLGN multi-unit neuronal responses to light stimuli were evaluated in multiple channels recorded from 6 rats (saline $n=60,0.5 \mathrm{mg} / \mathrm{kg} n=69,2 \mathrm{mg} / \mathrm{kg} n=71$; Figure 2). MPH administration significantly affected lightevoked ensemble activity (representative examples are shown in Figures $2 \mathrm{a}-\mathrm{c}$ ). MPH had an overall effect on the latency to response onset $(H=12.94, p=0.0015$; Figure $2 \mathrm{~d})$, and Dunn's test revealed that the $2 \mathrm{mg} / \mathrm{kg}$ dose significantly reduced onset latency compared with saline control $(p<0.05)$. An overall effect on the latency to reach the maximum peak response was also significant $(H=19.12$, $p<0.0001$; Figure 2e) with the $2 \mathrm{mg} / \mathrm{kg}$ dose decreasing the latency compared with control $(\mathrm{p}<0.05)$. MPH produced a dose-dependent increase in the maximum peak amplitude $(\mathrm{H}=12.97, p=0.0015$; Figure $2 \mathrm{f})$ with both doses increasing the amplitude as compared with control $(p<0.05)$, without significantly affecting total area of the primary response $(\mathrm{H}=4.910, p=0.0859$; Figure $2 \mathrm{~g})$.

\section{MPH Effects on Single-Unit Activity}

Single-unit responses were evaluated in the same manner as multi-unit ensembles (saline $n=28$ cells, $0.5 \mathrm{mg} / \mathrm{kg} n=25$ cells, $2 \mathrm{mg} / \mathrm{kg} n=31$ cells; see Figure 3 for representative examples). As seen with multi-unit activity, MPH broadly affected the properties of single-unit responses to light stimuli during task performance. MPH significantly shortened onset latency $(\mathrm{H}=7.696, p=0.0213$; Figure 3d) with Dunn's test indicating the $2 \mathrm{mg} / \mathrm{kg}$ dose 

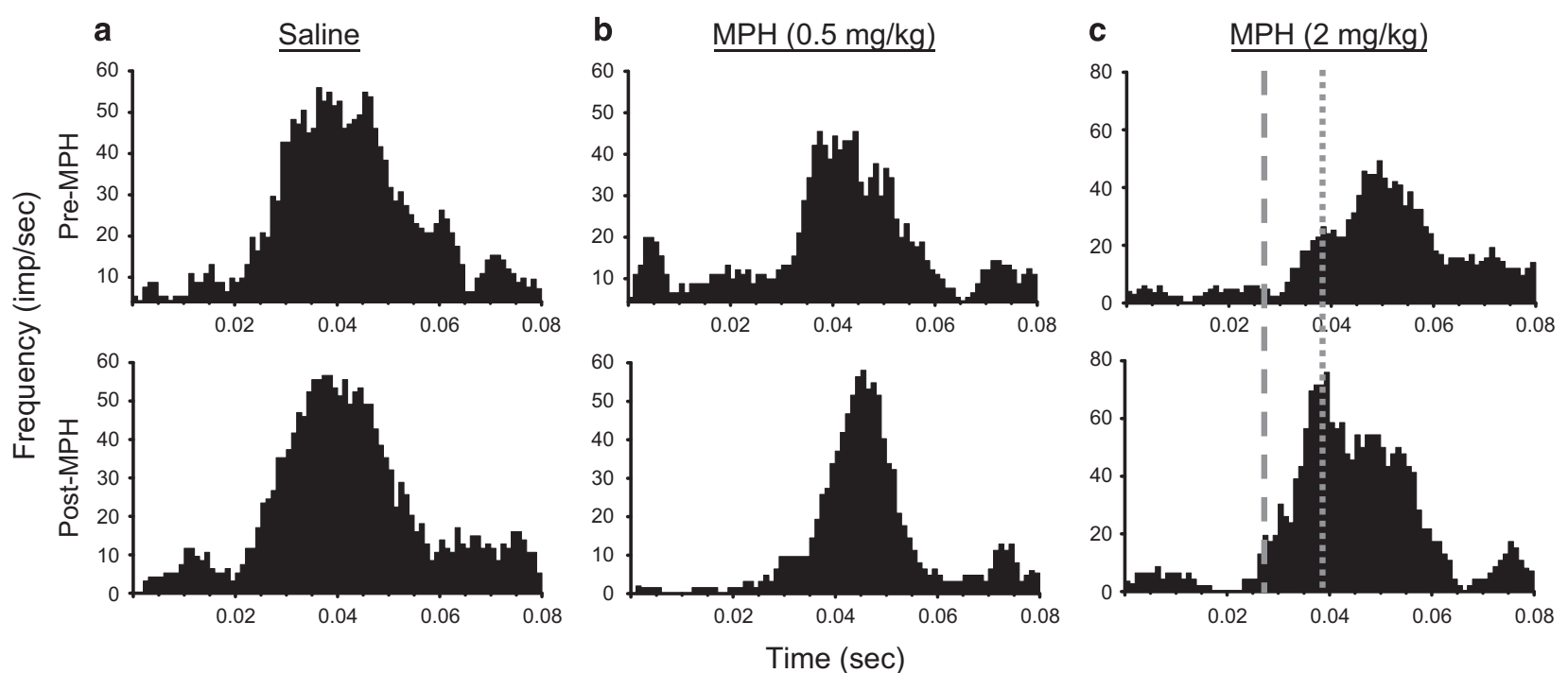

d

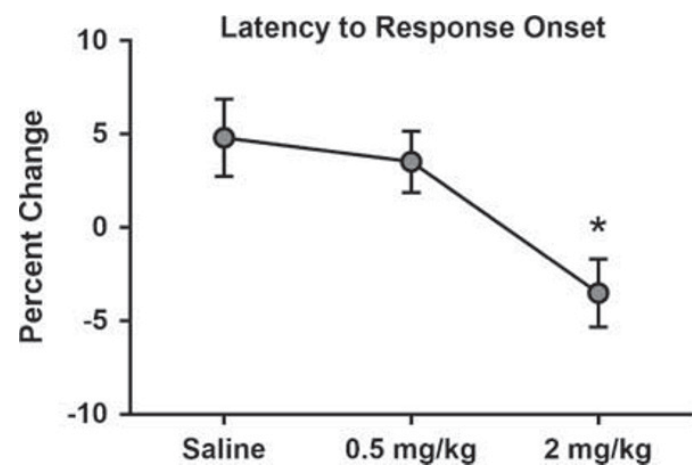

f

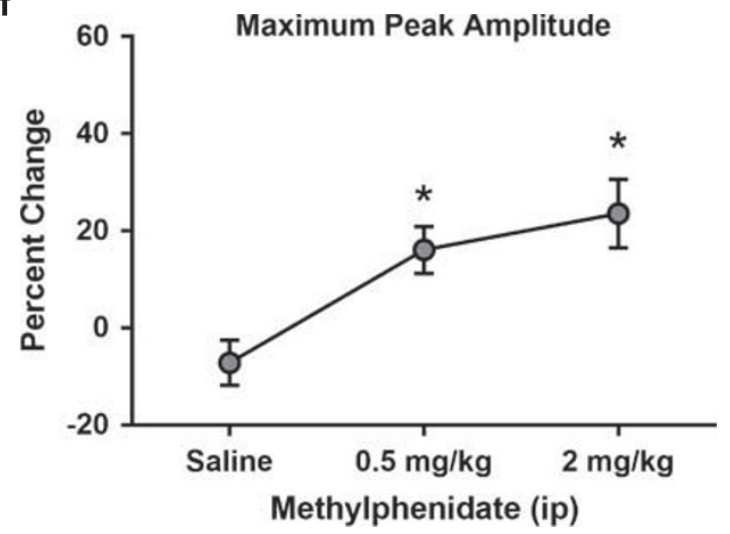

e
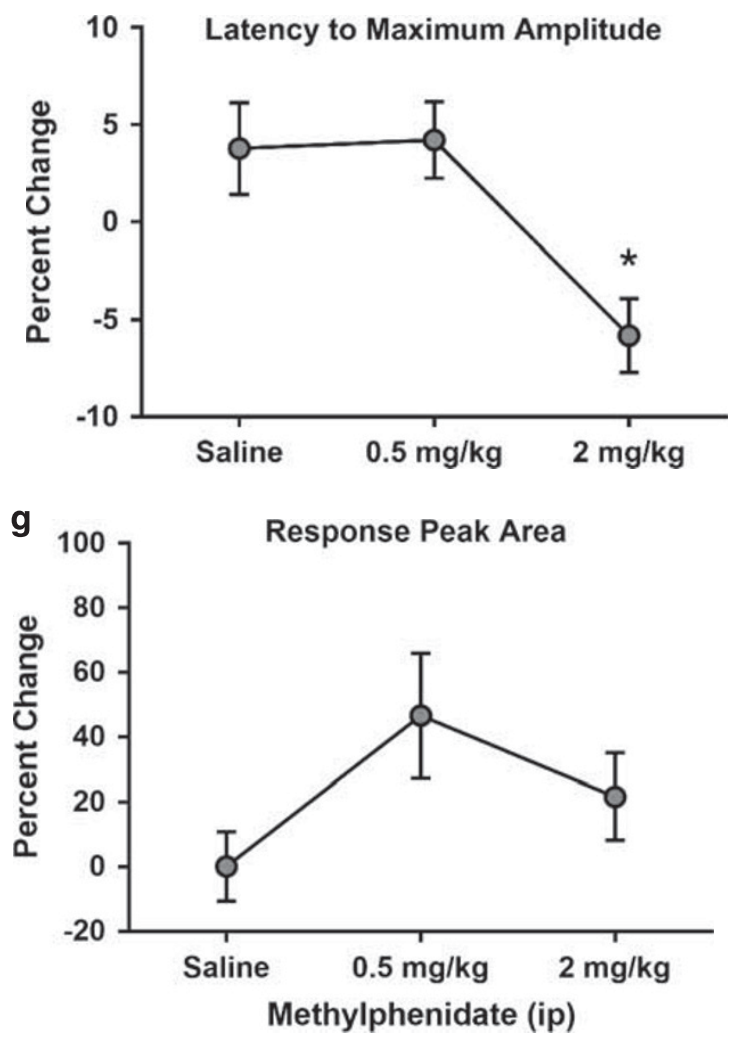

Figure $2 \mathrm{MPH}$ effects on multi-unit activity during performance of the visual signal detection task. (a-c) PSTHs illustrate the effects of saline, MPH (0.5 mg/ $\mathrm{kg})$, and $\mathrm{MPH}(2 \mathrm{mg} / \mathrm{kg}$ ) treatment (bottom) as compared with the pretreatment control condition (top) on evoked discharge of a multi-unit light-responsive channel within the dLGN. Histograms are aligned to stimulus onset (time =0) during pretreatment control (top; saline) and drug posttreatment (bottom; saline, 0.5 , and $2 \mathrm{mg} / \mathrm{kg}$ ) conditions. Dashed line: an example of decreased latency to response onset following drug after treatment. Dotted line: an example of decreased latency to peak response following drug after treatment. An increase in the maximum peak amplitude is apparent across the pre- and post-MPH PSTHs. (d-g) Line graphs represent percent change values \pm SEM for properties of dLGN multi-unit neuronal activity in response to light stimuli following a dose response $\mathrm{MPH}$ (saline $n=60$ channels, $0.5 \mathrm{mg} / \mathrm{kg} n=69$ channels, $2 \mathrm{mg} / \mathrm{kg} n=7 \mathrm{l}$ channels). (d, e) Percent change in latency to response onset and maximum peak response, respectively. (f, g) Percent change in maximum peak amplitude and response peak area. $* P<0.05$.

decreased the latency compared with control $(p<0.05)$. Although trends to decrease the latency to the maximum peak response and increase the maximum peak amplitude were apparent and resembled MPH effects observed on the multi-unit activity, these differences were not significant $(\mathrm{H}=3.139, p=0.2081$; Figure 3e and $\mathrm{H}=0.8750, p=0.6457$; Figure $3 \mathrm{f}$, respectively). Again, there were no effects on the response peak area following MPH treatment $(\mathrm{H}=0.2413, p=0.8864$; Figure $3 \mathrm{~g})$. 

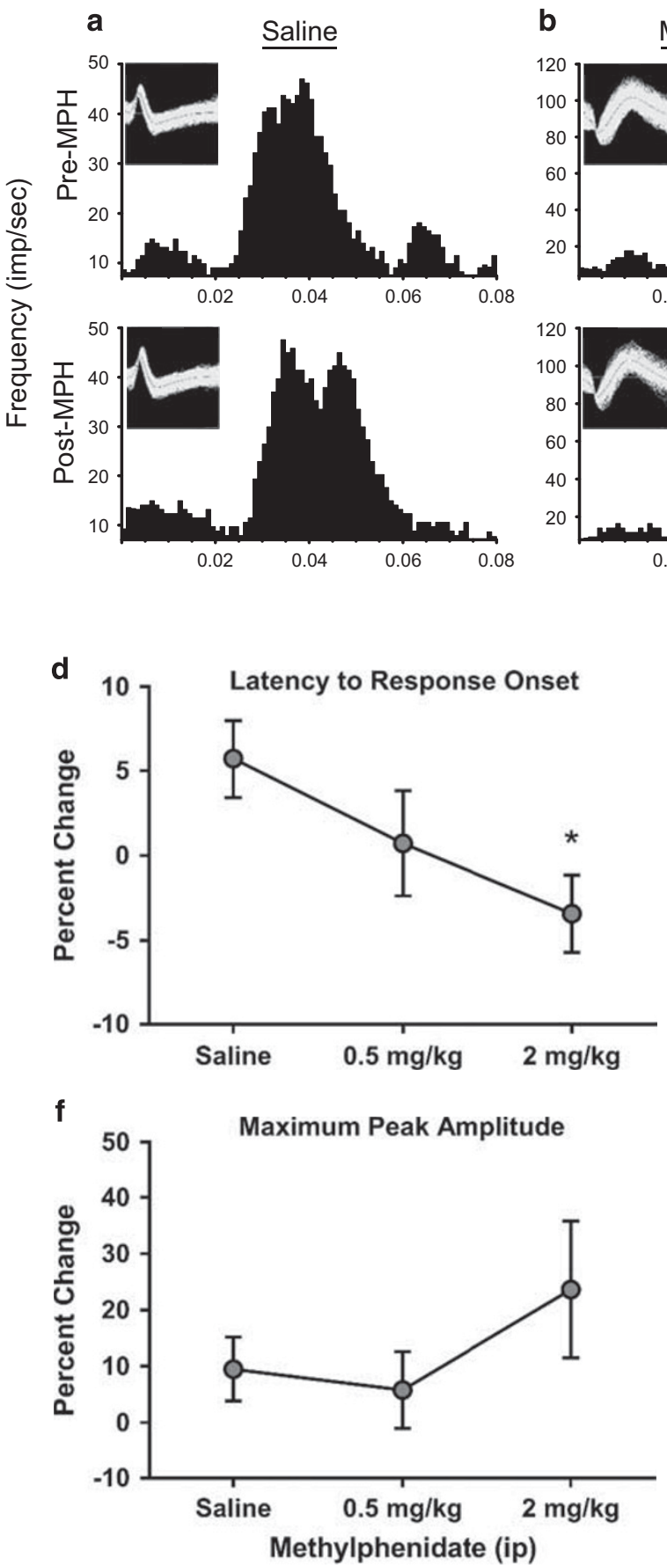
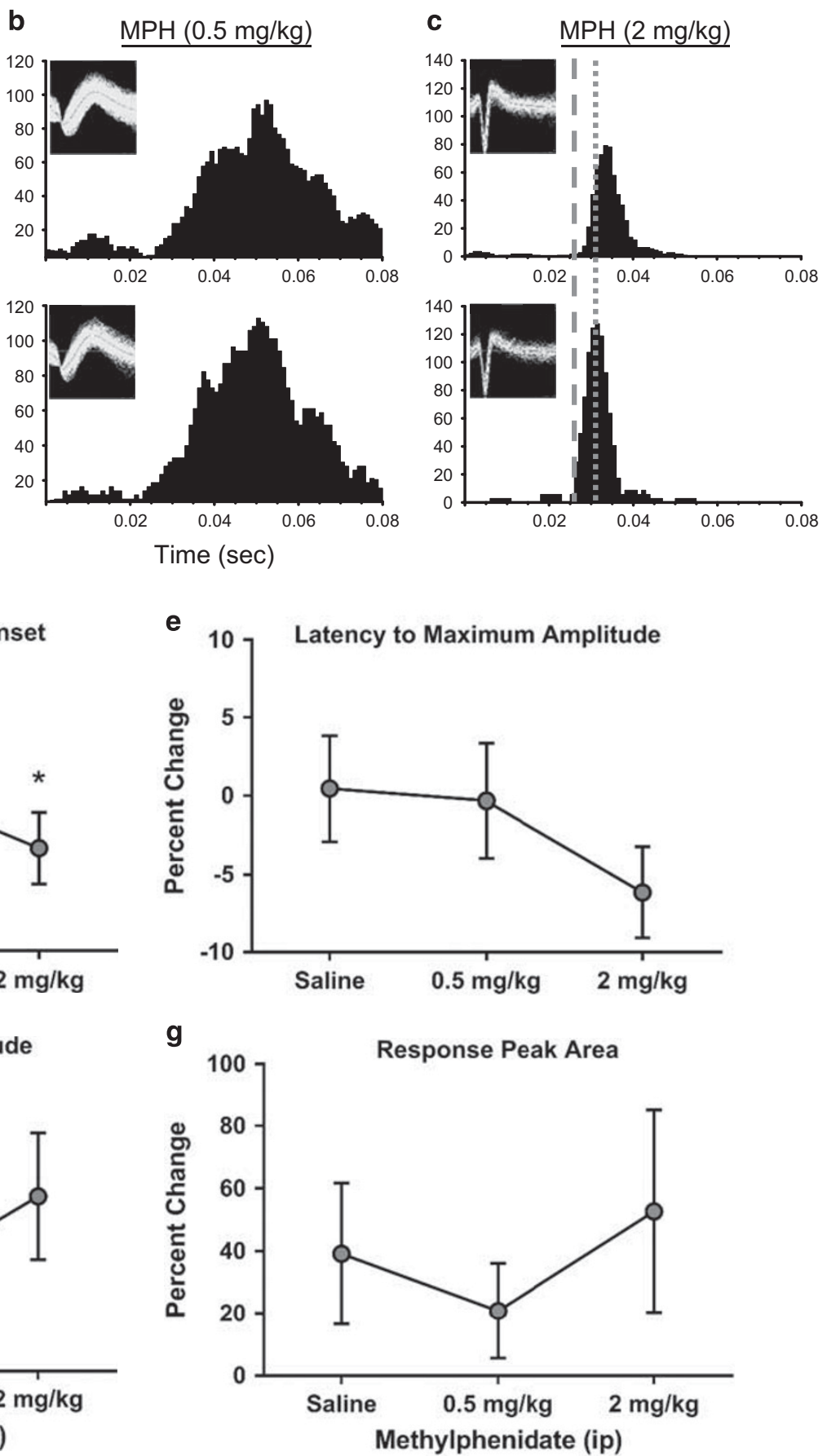

Figure $3 \mathrm{MPH}$ effects on single-unit activity during performance of the visual signal detection task. (a-c) PSTHs illustrate the effects of saline, MPH $(0.5 \mathrm{mg} / \mathrm{kg})$, and $\mathrm{MPH}(2 \mathrm{mg} / \mathrm{kg})$ treatment on evoked discharge of a single-unit light-responsive channel within the dLGN, respectively. Inset waveforms represent unit discrimination and recording across experimental conditions. Histograms are aligned to stimulus onset (time $=0$ ) during pretreatment control (top; saline) and drug posttreatment (bottom; saline, 0.5 , or $2 \mathrm{mg} / \mathrm{kg}$ ) conditions. Dashed line: an example of decreased latency to response onset following drug after treatment. Dotted line: an example of decreased latency to peak response following drug after treatment. An increase in the maximum peak amplitude is apparent across the pre- and post-MPH PSTHs. (d-g) Line graphs represent percent change values \pm SEM for properties of dLGN single-unit neuronal activity in response to light stimuli following a dose response MPH (saline $n=28$ cells, $0.5 \mathrm{mg} / \mathrm{kg} n=25$ cells, $2 \mathrm{mg} / \mathrm{kg} n=31$ cells). (d, e) Percent change in latency to response onset and maximum peak response, respectively. (f, g) Percent change in maximum peak amplitude and response peak area. $* P<0.05$.

\section{MPH Effects on VEPs and Oscillatory Activity}

The effects of MPH on VEPs to light stimuli within dLGN were evaluated (saline $n=14$ channels, $0.5 \mathrm{mg} / \mathrm{kg} n=15$ channels, $2 \mathrm{mg} / \mathrm{kg} n=18$ channels). VEPs were averaged from lightresponsive channels across all 6 rats (Figures $4 \mathrm{a}-\mathrm{c}$ show averaged waveforms, with an expanded timescale shown in insets). MPH administration significantly shortened the latency of the P30 wave $(H=9.156, p=0.0103$; Figure $4 d)$ with Dunn's test revealing a significant reduction in the P30 latency at the $2 \mathrm{mg} / \mathrm{kg}$ dose compared with saline control. $\mathrm{MPH}$ 
administration also significantly decreased the amplitude of the P30 ( $\mathrm{H}=7.611, p=0.0222$; Figure $4 \mathrm{e})$ with Dunn's test showing a drug-mediated decrease in amplitude of the P30 following the
$2 \mathrm{mg} / \mathrm{kg}$ dose compared with saline control. MPH had no significant effect on either the latency or the amplitude of the N54 $(\mathrm{H}=1.747, p=0.4175$; Figure $4 \mathrm{f}$ and $\mathrm{H}=2.787, p=0.2482$; a

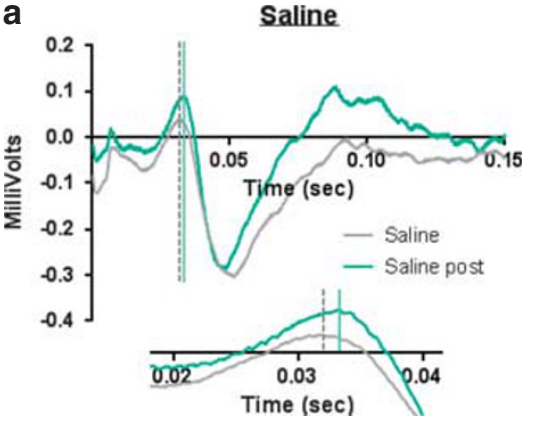

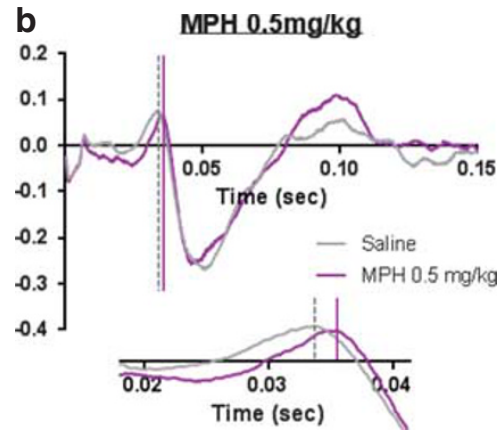

d
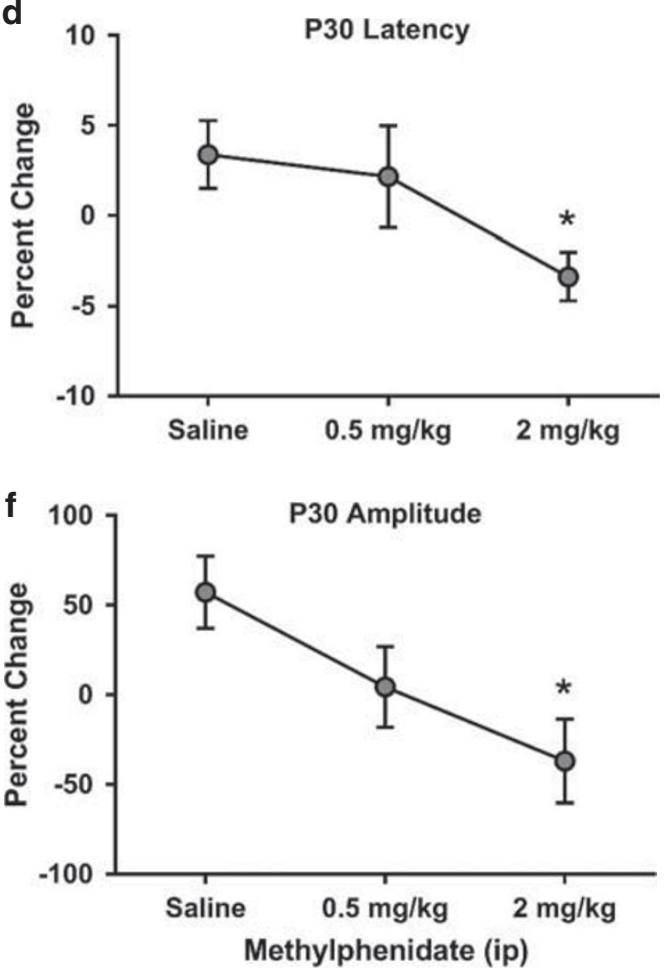

e
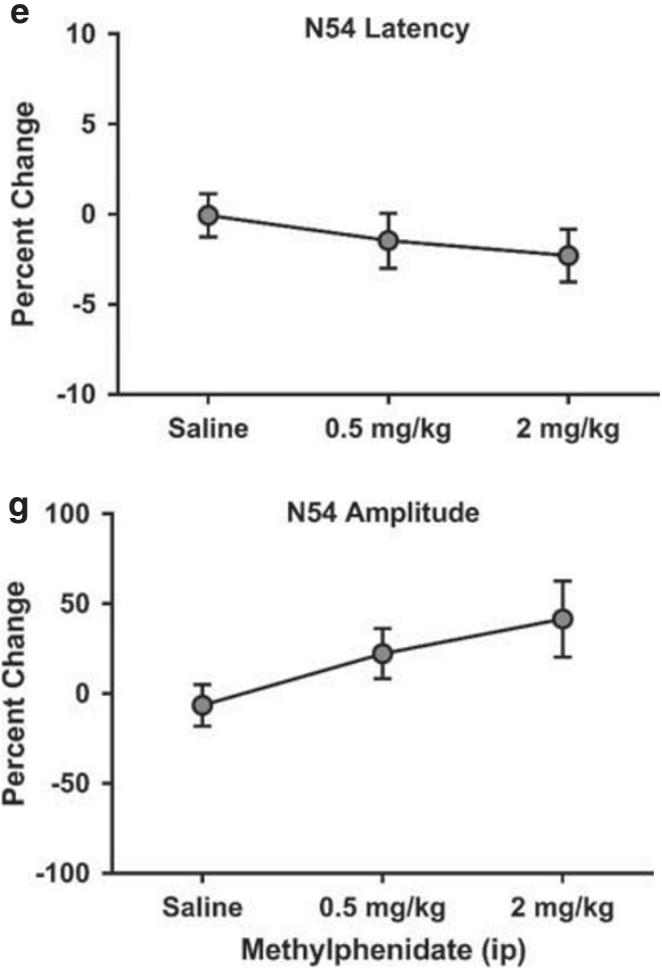

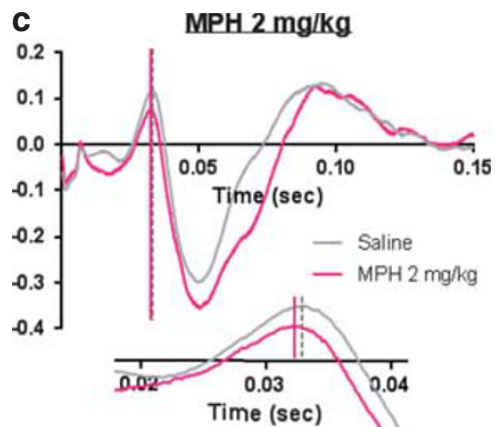

N54 Latency
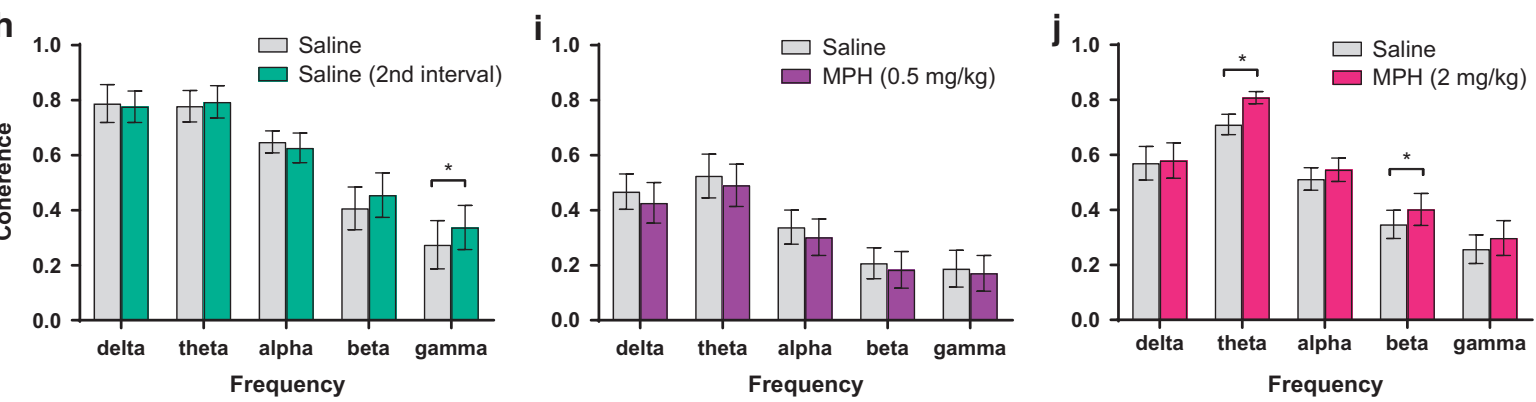

Figure $4 \mathrm{MPH}$ effects on visually-evoked potentials (VEPs) during performance of the visual signal detection task. (a-c) Representative VEPs on response to visual targets were averaged from light-responsive channels ((a) saline after treatment shown in green, $n=14$ channels, (b) MPH $0.5 \mathrm{mg} / \mathrm{kg}$ shown in purple, $n=15$ channels, and (c) MPH $2 \mathrm{mg} / \mathrm{kg}$ shown in magenta, $n=18$ channels, all compared with baseline values following saline treatment from run I in gray). VEPs generally exhibited a prominent P30, a positive deflection of the waveform occurring $30 \mathrm{~ms}$ after the onset of target stimulus presentation, and an N54, a negative deflection of the waveform occurring $54 \mathrm{~ms}$ following the onset of stimulus presentation. Waveforms were plotted for the full VEP waveform and insets show expanded timescales (20-40 ms) to highlight differences observed at the P30 response. (d-g) Line graphs represent percent change values \pm SEM for properties of VEP waveforms to light stimuli. (d, f) Percent change in latency to P30 and N54 responses, respectively. (e, g) Percent change in amplitude of P30 and N54 responses. ( $h-j)$ Treatment-induced effects on coherence of dLGN oscillatory activity across averaged frequency bands shown in bar graphs \pm SEM following saline, $\mathrm{MPH}(0.5 \mathrm{mg} / \mathrm{kg})$, and $\mathrm{MPH}(2 \mathrm{mg} / \mathrm{kg})$, respectively. ${ }^{*} \mathrm{P}<0.05$. 
Figure 4g). There was a main effect of frequency ( $F$ $(4,40)=35.59, p<0.0001)$ and a frequency $\times$ treatment interaction $(\mathrm{F}(4,40)=3.777, p=0.0107)$ with an increase within the gamma band $(p=0.0096)$ between saline administration intervals. There was an effect of frequency $(\mathrm{F}(4,56)=21.61$, $p<0.0001)$, but no treatment effects when $\mathrm{MPH}(0.5 \mathrm{mg} / \mathrm{kg})$ was evaluated. Frequency $(\mathrm{F}(4,76)=27.2, p<0.0001)$ and frequency $\times$ treatment interaction $(\mathrm{F}(4,76)=3.677, p=0.0086)$ effects were found at the $2 \mathrm{mg} / \mathrm{kg}$ dose of $\mathrm{MPH}$, with significant increases in coherence within the theta and beta bands $(p<0.0001$ and $p=0.0097$, respectively).

\section{Associations between Behavioral and Electrophysiological Measures}

To further investigate the relation of behavioral changes to $\mathrm{MPH}$ action within the dLGN, the percent change from interval one (saline) to interval two (saline, 0.5 , or $2 \mathrm{mg} / \mathrm{kg}$ $\mathrm{MPH}$ ) of reaction times to make correct responses on signal trials were compared with the response latencies to reach the first response peak within single-unit, multi-unit, and VEP activity (Figure 5). Although percent changes in the latency of unit activity to reach the maximum response did not correlate with hit reaction latency (single-unit; $r=0.1001$, $p=0.6927$ or multi-unit; $r=0.0609, p=0.8103$ ), changes in VEP latency to reach the P30 deflection were highly correlated with hit reaction latency $(r=0.6491, p=0.0036)$.

\section{DISCUSSION}

The present experiments employed a paradigm designed to simultaneously evaluate electrophysiological correlates of early-stage sensory processing and measures of performance during signal detection behavior in normal rats. Administration of $\mathrm{MPH}$, which blocks reuptake of NE and DA, altered multiple indices of light-evoked neuronal responses and VEPs to target lights within the dLGN of rats during task performance. First, latencies to response onset and to the peak of the response were decreased. Second, the peak intensity of stimulus-evoked discharge was increased. These findings indicate that both the speed and strength of signal transmission through the dLGN as measured by single-cell and ensemble neuronal responses were improved by MPH during task performance. In addition, the time to reach the first positive deflection of the VEP in response to target stimuli decreased, whereas theta and beta oscillatory activity coherence increased within the dLGN. These changes in signal processing were observed at the same dose of $\mathrm{MPH}$ ( $2 \mathrm{mg} / \mathrm{kg})$ that enhanced behavioral performance, as indicated by reduced reaction times for making correct responses within the task. Improvements in reaction speed were highly correlated with faster VEP latencies. Finally, immunostaining showed that dLGN is densely innervated by noradrenergic fibers with no evidence of dopaminergic input (Supplementary Figure S1). Given the ability of $\mathrm{MPH}$ to improve cognitive performance in humans and in rodent assays of attention, these results suggest that augmentation of sensory transmission mediated through noradrenergic mechanisms may contribute significantly to the performance enhancing effects of psychostimulant drugs.

\section{The Impact of MPH on Signal Detection Behavior}

Collectively, the data suggest that MPH improved behavioral performance within the task; that is, although it did not improve accuracy, MPH did reduce latency to make correct responses. Rats were highly trained in the task, routinely achieving $>90 \%$ accuracy before drug testing. As a result, performance accuracy had already reached a ceiling that did not allow for a sufficient therapeutic window to observe facilitating effects. Nonetheless, the observed decrease in reaction time is characteristic of $\mathrm{MPH}$; $\mathrm{MPH}$-induced reduction in correct response latency agrees with multiple studies demonstrating improved reaction times on signal detection tasks in both rats and humans following $\mathrm{MPH}$ administration (Bizarro et al, 2004; Coghill et al, 2014; Eagle et al, 2007; Nandam et al, 2011; Navarra et al, 2008; Spencer et al, 2009). These findings suggest that although the percentage of correct responses did not change, correct responses were made with greater efficiency.

Upon closer inspection of the data, quantification of reaction time latencies revealed a general increase in reaction time in the second run of the task as compared with the first following saline administration. This increased latency effect
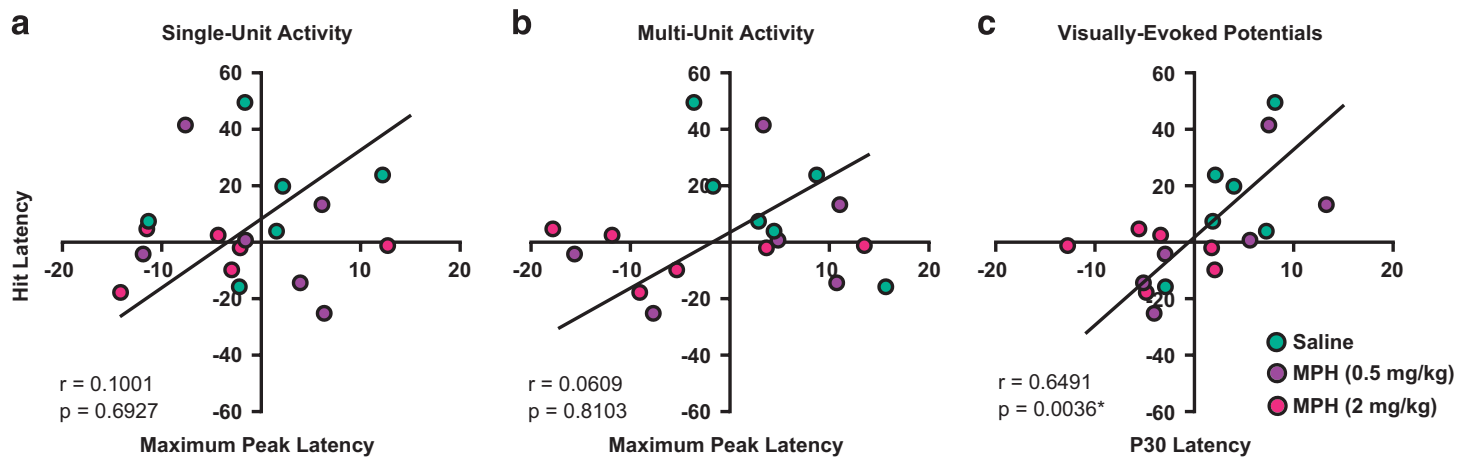

Figure 5 Association between behavioral and electrophysiological measures. (a-c) Scatter plots represent treatment-induced percent change in the latency to make hit responses versus the latency to reach the first peak response across levels of electrophysiological recordings; single-unit activity, multi-unit activity, and visually-evoked potentials, respectively. Green-filled circles represent the percent change following saline treatment, purple-filled circles are following MPH $(0.5 \mathrm{mg} / \mathrm{kg})$, and magenta-filled circles are following MPH ( $2 \mathrm{mg} / \mathrm{kg})$ for each animal ( $n=6$ for each treatment). Spearman's $r$ and $p$-values for each correlation are reported in insets of each plot with the reduced major axis (model II regression; Sokal and Rohlf, 1995). * $P<0.05$. 
may result from the testing paradigm that requires animals to perform two runs of the task for the purpose of comparing electrophysiological and behavioral measures from each animal with their own baseline for each testing day. According to this protocol, animals may collect up to 100 water rewards before the second run. Although this feature of the experimental paradigm may reduce motivational state during the second run of the task leading to longer response times, it is apparent from the data that MPH administration not only diminishes latency increases $(0.5 \mathrm{mg} / \mathrm{kg})$ but actually decreases reaction time $(2 \mathrm{mg} / \mathrm{kg})$ in the second run of the task as compared with the first (see Figure 1c).

\section{The Impact of MPH on Electrophysiological Indices of Sensory Signal Processing}

For all levels of electrophysiological analysis that were performed, the results broadly match those of the behavioral study. The same dose of MPH $(2 \mathrm{mg} / \mathrm{kg})$ that enhanced behavioral performance also enhanced measures of lightevoked activity. Most prominently, latencies of single- and multiple-unit discharges and VEPs in response to task light stimuli were decreased, indicating that when MPH was on board the neural mechanisms activated at cellular and circuit levels of the dLGN were engaged more quickly following stimulus presentation. Although not as prominent as observed with behavioral latencies to make correct responses (Figure 1), a general slowing of electrophysiological response latencies from the first run to the second following saline is evident in Figures 2, 3 and 4. We again attribute these slowing effects to a decrease in overall motivation and, therefore, central arousal state during performance of the second run. Nonetheless, MPH again attenuates general slowing of responses at $0.5 \mathrm{mg} / \mathrm{kg}$ and reduces latencies at $2 \mathrm{mg} / \mathrm{kg}$ (Figures $2 \mathrm{~d}$ and e, $3 \mathrm{~d}$ and $4 \mathrm{~d}$ ).

Multi-unit data is an often overlooked measure that allows the study of experimental manipulations on neuronal responsiveness over a localized population of cells within a specified circuit or across a neural network as opposed to individual unit activity. In most cases, multi-unit activity has been shown to mirror the activity and the changes in activity that occur at the single-unit level (Devilbiss et al, 2006). It may in fact be the case that compared with data from single units, recordings from ensembles of neurons give a more accurate representation and key to understanding the dynamics of information processing in brain regions of waking animals during performance of complex behavioral tasks (Nicolelis and Lebedev, 2009). In the present study, the most dramatic and consistent benefit of $\mathrm{MPH}$ on light stimulus-evoked neuronal discharge within the dLGN of rats performing the visual signal detection task was evident in ensemble neuronal activity, although the same patterns were reflected in the single-unit data.

\section{MPH Effects Resemble Noradrenergic Actions in LC Terminal Fields}

The effects of MPH on the speed and strength of dLGN neuronal responses to light stimuli are strikingly similar to the well-documented modulatory effects of the LC-NE pathway on individual neuron and neural circuit responses to afferent synaptic inputs (Berridge and Waterhouse, 2003). For example, when concentrations of NE were elevated by tonic activation of the LC, the temporal properties of whisker pad stimulusevoked responses within the ventroposterior medial thalamus and barrel field cortex were reduced by 1-3 ms (Devilbiss and Waterhouse, 2004). In addition, early work by Rogawski and Aghajanian (1980a, b), showed that both LC stimulation and local iontophoretic application of NE enhanced the magnitude of synaptic excitation of dLGN neurons.

In addition to latency and magnitude changes, the boundaries of the light-evoked responses were sharpened following MPH. As shown in Figure 2c, the response peak slowly ramps up and continues to trail off after reaching maximum amplitude in the saline condition, whereas with $\mathrm{MPH}$ treatment there is a clear termination of the response after reaching maximum amplitude. Thus, MPH changes the structure of the sensory-evoked response so that it is more focused, an effect observed previously following local NE application in the visual cortex (Waterhouse et al, 1990) or systemic MPH administration in the somatosensory cortex (Drouin et al, 2007). This effect, combined with greater coherence of local oscillatory activity, would be expected to tighten the response synchrony of dLGN neurons, thereby strengthening output from thalamus to cortex and facilitating higher-order processing (Alonso et al, 1996).

The similarity of outcomes resulting from our previous work in the anesthetized rat and the current report in behaving animals indicates that $\mathrm{MPH}$ produces NE-like amplification of neural signals (Navarra et al, 2013). In addition, our immunohistochemical findings indicate that catecholamine innervation of the rat dLGN is exclusively noradrenergic. Although MPH blocks reuptake of both NE and DA, the absence of dopaminergic fibers in the dLGN suggests the observed MPH-induced modulation of lightevoked activity is mediated locally by $\mathrm{NE}$ and not DA neurotransmission. As alluded to above, the data do not rule out the possibility of DA-mediated effects occurring remote from but afferent to the dLGN. Importantly, the current work is the first to demonstrate drug-induced NE-like modulation of light-evoked responses to stimuli necessary for goal directed performance within a visual signal detection task.

\section{MPH Effects Resemble Attention-Mediated Modulation of Sensory Processing Circuits}

The observed modulations of dLGN responsiveness by MPH also resemble top-down mediated alterations in the timing and magnitudes of sensory responses within visual thalamic areas of monkeys and humans (Kastner and Pinsk, 2004; O'Connor et al, 2002; Saalmann and Kastner, 2009). Attentional modulation of single-cell activity within the LGN was first demonstrated in monkeys by McAlonan et al (2008). In this report, the magnitudes of evoked discharge in response to attended versus unattended cues were enhanced during performance of a visual attention task. Attention has also been shown to decrease the latency and increase the magnitude of cellular responses, while decreasing latency and magnitude of the first deflection of the VEP response within the visual cortex of monkeys performing a visual target detection task (Sundberg et al, 2012). Thus, MPH effects on dLGN neuronal responses and VEPs mimic top-down influences of selective attention. 
The LFP waveform is influenced by magnitude, sign, spatial proximity, and temporal coordination of current sources, and it is generally accepted that postsynaptic potentials contribute most heavily to the LFP (Meeren et al, 1998). Sundberg et al (2012) proposed that attentional influences place the circuit in an alerted state so that target stimuli trigger an already 'primed' sensory processing network, resulting in quicker responses. As the cell membranes are depolarized before the arrival of afferent input, less change in magnitude of the initial deflection of the VEP is observed because of lesser synaptic driving force. It is reasonable to extend this explanation to the effects observed here given the well-described attention-enhancing actions of $\mathrm{MPH}$. Accordingly, MPH-mediated blockade of catecholamine reuptake leads to elevated extracellular concentrations of NE and DA that via their modulatory actions may serve to prime sensory circuits for receipt of stimulus-driven afferent input. As described above, it is possible that ascending and descending systems converge and exert synergistic influences on responses of single thalamic neurons to incoming stimuli (Groh et al, 2014). Thus, although cortical input likely enhances thalamic responsiveness to afferent input as a 'topdown' mechanism and is a plausible dimension of the natural state of goal-directed behaviors, we postulate that $\mathrm{MPH}$ modulates this already strengthened activity further through enhanced NE neurotransmission. In fact, these complimentary influences may be further illuminated by a recent hypothesis defining levels of oscillatory synchronization within a sensory stream, 'Communication through Coherence' (CTC) (Fries, 2015). According to CTC, betafrequency synchronization relays top-down attentional control, whereas theta-synchronization modulates higher visual areas through bottom-up influences. Data in the present report are agreement with this hypothesis, as the observed increases in coherence following MPH in both theta and beta frequencies may reflect the drug's potentiation of both cortical (top-down) and LC (bottom-up) pathways that converge in the thalamus. Combined, the reports cited above strongly suggest similarity between the effects of attention on the magnitude of responses to visual targets in goal-directed tasks and MPH modulation of visual responses to target stimuli within the dLGN of rats during performance of a signal detection task.

\section{Associations between Behavioral and Electrophysiological Measures}

Behavioral latency changes were significantly correlated with alterations in the latency of the first deflection of VEPs (Figure 5c), but not with alterations in single-unit or multi-unit light-evoked responses (Figures 5a and b, respectively). Given our findings across various parameters, it was expected that a majority of electrophysiological measures would correlate with behavioral outcomes. Indeed, the broader scale VEP responses may offer a clearer representation of signal processing within the dLGN network and provide more informative data in terms of correlative effects with behavior. In other words, as the electrophysiological metric within the dLGN becomes more representative of circuit-level activity, correlations between dLGN responsiveness and behavioral efficiency emerge.
The distribution of values in Figure 5 reinforces the tendency described above for behavioral reaction and electrophysiological response latencies to increase from the first to the second trial in control conditions and the ability of $\mathrm{MPH}$ to not only prevent these losses in function, but further improve function. MPH effects on both measures are most powerfully illustrated in Figure $5 \mathrm{c}$. Whereas percent changes following saline treatment all seem to cluster toward positive quadrants of the graph, percent changes of $\mathrm{MPH}$ $(2 \mathrm{mg} / \mathrm{kg})$ cluster toward negative quadrants while $\mathrm{MPH}$ $(0.5 \mathrm{mg} / \mathrm{kg})$ are somewhat scattered throughout.

\section{Clinical Significance}

The present work demonstrates the potential for psychostimulant agents to speed transmission and strengthen neuronal responsiveness to visual stimuli in the dLGN, while improving performance of a visual signal detection task. As such, sensory enhancement appears to be a significant component of the performance enhancing effects of $\mathrm{MPH}$ and a major reason for the desirability of the drug in individuals seeking to improve outcomes in goal-directed behavior. In this context, it is well to remember that the observed facilitating effects of MPH were observed in normal laboratory rats. The current results suggest that $\mathrm{MPH}$ engages intrinsic noradrenergic mechanisms to enhance the normal signal processing operations of sensory neurons and sensory neural circuits that impact performance.

\section{FUNDING AND DISCLOSURE}

The authors declare no conflict of interest.

\section{ACKNOWLEDGMENTS}

We thank Luke Mitchell for his assistance in analyzing visual-evoked potentials. This work has been supported by NIDA R01DA017960 (to BDW), NIDA F31DA037651 (to RLN), and a PhRMA Foundation Pre-Doctoral Award 270397 (to RLN).

\section{REFERENCES}

Agster KL, Clark BD, Gao W-J, Shumsky JS, Wang HX, Berridge CW et al (2011). Experimental strategies for investigating psychostimulant drug actions and prefrontal cortical function in ADHD and related attention disorders. Anat Rec 294: 1698-1712.

Alonso J-M, Usrey WM, Reid RC (1996). Precisely correlated firing in cells of the lateral geniculate nucleus. Nature 383: 815-819.

Berridge CW, Devilbiss DM, Andrzejewski ME, Arnsten AFT, Kelley AE, Schmeichel B et al (2006). Methylphenidate preferentially increases catecholamine neurotransmission within the prefrontal cortex at low doses that enhance cognitive function. Biol Psychiatry 60: 1111-1120.

Berridge CW, Shumsky JS, Andrzejewski ME, McGaughy JA, Spencer RC, Devilbiss DM et al (2012). Differential sensitivity to psychostimulants across prefrontal cognitive tasks: differential involvement of noradrenergic $\alpha 1$ - and $\alpha 2$-receptors. Biol Psychiatry 71: 467-473.

Berridge CW, Waterhouse BD (2003). The locus coeruleusnoradrenergic system: modulation of behavioral state and statedependent cognitive processes. Brain Res Rev 42: 33-84. 
Bizarro L, Patel S, Murtagh C, Stolerman IP (2004). Differential effects of psychomotor stimulants on attentional performance in rats: nicotine, amphetamine, caffeine and methylphenidate. Behav Pharmacol 15: 195-206.

Coghill DR, Seth S, Pedroso S, Usala T, Currie J, Gagliano A (2014). Effects of methylphenidate on cognitive functions in children and adolescents with attention-deficit/hyperactivity disorder: evidence from a systematic review and a meta-analysis. Biol Psychiatry 76: 603-615.

Devilbiss DM, Page ME, Waterhouse BD (2006). Locus ceruleus regulates sensory encoding by neurons and networks in waking animals. J Neurosci 26: 9860-9872.

Devilbiss DM, Waterhouse BD (2003). Determination of drug actions on multiple simultaneously recorded neurons across functionally connected networks. In: Waterhouse BD (ed). Methods in Drug Abuse Research: Cellular and Circuit Level Analyses. CRC Press: Boca Raton, FL, pp 213-238.

Devilbiss DM, Waterhouse BD (2004). The effects of tonic locus ceruleus output on sensory-evoked responses of ventral posterior medial thalamic and barrel field cortical neurons in the awake rat. J Neurosci 24: 10773-10785.

Drouin C, Wang D, Waterhouse BD (2007). Neurophysiological actions of methylphenidate in the primary somatosensory cortex. Synapse 61: 985-990.

Eagle DM, Tufft MR, Goodchild HL, Robbins TW (2007). Differential effects of modafinil and methylphenidate on stopsignal reaction time task performance in the rat, and interactions with the dopamine receptor antagonist cis-flupenthixol. Psychopharmacology 192: 193-206.

Franke AG, Bagusat C, Rust S, Engel A, Lieb K (2014). Substances used and prevalence rates of pharmacological cognitive enhancement among healthy subjects. Eur Arch Psychiatry Clin Neurosci 264: 014-0537.

Fries P (2015). Rhythms for cognition: communication through coherence. Neuron 88: 220-235.

Fukuda Y, Sumitomo I, Sugitani M, Iwama K (1979). Receptivefield properties of cells in the dorsal part of the albino rat's lateral geniculate nucleus. Jpn J Physiol 29: 283-307.

García-Cabezas M, Martínez-Sánchez P, Sánchez-González M, Garzón M, Cavada C (2009). Dopamine innervation in the thalamus: monkey versus rat. Cereb Cortex 19: 424-434.

Groh A, Bokor H, Mease RA, Plattner VM, Hangya B, Stroh A et al (2014). Convergence of cortical and sensory driver inputs on single thalamocortical cells. Cereb Cortex 24: 3167-3179.

Howell DC (2008). Fundamental Statistics for the Behavioral Sciences. Wadsworth Press/Thompson Learning: Belmont, CA.

Jentsch JD, Aarde SM, Seu E (2009). Effects of atomoxetine and methylphenidate on performance of a lateralized reaction time task in rats. Psychopharmacology 202: 497-504.

Jonkman LM, Kemner C, Verbaten MN, Koelega HS, Camfferman G, vd Gaag R-J et al (1997). Effects of methylphenidate on eventrelated potentials and performance of attention-deficit hyperactivity disorder children in auditory and visual selective attention tasks. Biol Psychiatry 41: 690-702.

Kastner S, Pinsk MA (2004). Visual attention as a multilevel selection process. Cogn Affect Behav Neurosci 4: 483-500.

Kayama Y (1985). Ascending, descending and local control of neuronal activity in the rat lateral geniculate nucleus. Vision Res 25: 339-347.

Kim S, Chen S, Tannock R (2014). Visual function and color vision in adults with attention-deficit/hyperactivity disorder. J Optom 7: 22-36.

Kimchi EY, Laubach M (2009). Dynamic encoding of action selection by the medial striatum. J Neurosci 29: 3148-3159.

Kromer LF, Moore RY (1980). A study of the organization of the locus coeruleus projections to the lateral geniculate nuclei in the albino rat. Neuroscience 5: 255-271.

Kuczenski R, Segal DS (2001). Locomotor effects of acute and repeated threshold doses of amphetamine and methylphenidate: relative roles of dopamine and norepinephrine. J Pharmacol Exp Ther 296: 876-883.

Martin L, Aring E, Landgren M, Hellstrom A, Andersson Gronlund $M$ (2008). Visual fields in children with attention-deficit/ hyperactivity disorder before and after treatment with stimulants. Acta Ophthalmol 86: 259-264.

Mazer JA (2011). Spatial attention, feature-based attention, and saccades: three sides of one coin? Biol Psychiatry 69: $1147-1152$.

McAlonan K, Cavanaugh J, Wurtz RH (2008). Guarding the gateway to cortex with attention in visual thalamus. Nature 456: 391-394.

McGaughy J, Sarter M (1995). Behavioral vigilance in rats: task validation and effects of age, amphetamine, and benzodiazepine receptor ligands. Psychopharmacology 117: 340-357.

Meeren HK, Van Luijtelaar EL, Coenen AM (1998). Cortical and thalamic visual evoked potentials during sleep-wake states and spike-wave discharges in the rat. Electroencephalogr Clin Neurophysiol 108: 306-319.

Nandam LS, Hester R, Wagner J, Cummins TD, Garner K, Dean AJ et al (2011). Methylphenidate but not atomoxetine or citalopram modulates inhibitory control and response time variability. Biol Psychiatry 69: 902-904.

Navarra R, Graf R, Huang Y, Logue S, Comery T, Hughes Z et al (2008). Effects of atomoxetine and methylphenidate on attention and impulsivity in the 5-choice serial reaction time test. Prog Neuropsychopharmacol Biol Psychiatry 32: 34-41.

Navarra RL, Clark BD, Zitnik GA, Waterhouse BD (2013). Methylphenidate and atomoxetine enhance sensory-evoked neuronal activity in the visual thalamus of male rats. Exp Clin Psychopharmacol 21: 363-374.

Nicolelis MA, Lebedev MA (2009). Principles of neural ensemble physiology underlying the operation of brain-machine interfaces. Nat Rev Neurosci 10: 530-540.

O'Connor DH, Fukui MM, Pinsk MA, Kastner S (2002). Attention modulates responses in the human lateral geniculate nucleus. Nat Neurosci 5: 1203-1209.

Paterson NE, Ricciardi J, Wetzler C, Hanania T (2011). Sub-optimal performance in the 5-choice serial reaction time task in rats was sensitive to methylphenidate, atomoxetine and d-amphetamine, but unaffected by the COMT inhibitor tolcapone. Neurosci Res 69: 41-50.

Pfeiffer B, Daly BP, Nicholls EG, Gullo DF (2015). Assessing sensory processing problems in children with and without attention deficit hyperactivity disorder. Phys Occup Ther Pediatr 35: $1-12$.

Robinson E (2012). Blockade of noradrenaline re-uptake sites improves accuracy and impulse control in rats performing a fivechoice serial reaction time tasks. Psychopharmacology 219: 303-312.

Rogawski MA, Aghajanian GK (1980a). Activation of lateral geniculate neurons by norepinephrine: mediation by an $\alpha$-adrenergic receptor. Brain Res 182: 345-359.

Rogawski MA, Aghajanian GK (1980b). Modulation of lateral geniculate neurone excitability by noradrenaline microiontophoresis or locus coeruleus stimulation. Nature 287: 731-734.

Saalmann YB, Kastner S (2009). Gain control in the visual thalamus during perception and cognition. Curr Opin Neurobiol 19: 408-414.

Sahakian BJ, Morein-Zamir S (2015). Pharmacological cognitive enhancement: treatment of neuropsychiatric disorders and lifestyle use by healthy people. Lancet Psychiatry 2: 357-362.

Sokal RR, Rohlf FJ (1995). Biometry. WH Freeman \& Co: New York. Spencer SV, Hawk LW Jr, Richards JB, Shiels K, Pelham WE Jr, Waxmonsky JG (2009). Stimulant treatment reduces lapses in attention among children with ADHD: the effects of methylphenidate on intra-individual response time distributions. J Abnorm Child Psychol 37: 805-816. 
Sundberg KA, Mitchell JF, Gawne TJ, Reynolds JH (2012). Attention influences single unit and local field potential response latencies in visual cortical area V4. J Neurosci 32: 16040-16050.

Svetlov SI, Kobeissy FH, Gold MS (2007). Performance enhancing, non-prescription use of Ritalin: a comparison with amphetamines and cocaine. J Addict Dis 26: 1-6.

Volkow ND, Fowler JS, Wang G, Ding Y, Gatley SJ (2002). Mechanism of action of methylphenidate: insights from PET imaging studies. J Atten Disord 6(Suppl 1): S31-S43.
Waterhouse BD, Azizi SA, Burne RA, Woodward DJ (1990). Modulation of rat cortical area 17 neuronal responses to moving visual stimuli during norepinephrine and serotonin microiontophoresis. Brain Res 514: 276-292.

Weyandt LL, Oster DR, Marraccini ME, Gudmundsdottir BG, Munro BA, Zavras BM et al (2014). Pharmacological interventions for adolescents and adults with ADHD: stimulant and nonstimulant medications and misuse of prescription stimulants. Psychol Res Behav Manag 7: 223-249.

Supplementary Information accompanies the paper on the Neuropsychopharmacology website (http://www.nature.com/npp) 